\title{
Profiles synthesis through radii variation of arcs profile method
}

\author{
Tomáš Lack ${ }^{1}$ and Juraj Gerlici ${ }^{1, *}$ \\ ${ }^{1}$ University of Žilina, Faculty of Mechanical Engineering, Department of Transport and Handling \\ Machines, Univerzitná 8215/1, 01026 Žilina, Slovak Republic.
}

\begin{abstract}
The article deals with one of the ways of profile geometry design of a railway wheel and rail. The base for the creation of a new profile is an interactive attitude based on the modification of ,the original shape which is defined by section of a railway wheel profile", with to each other connected and exactly defined arcs radii. It is possible to change them according to shape needs of the final geometrical characteristics. Problems of the railway wheel/rail contact represents a basic point of any analysis which is connected with the moment of a railway vehicle on a track, with safety, speed, with comfort of people and goods transport. It is connected with the construction of new railway vehicles, with the reconstruction the old ones, with the approval (refusal) of vehicles into operation, with their evaluation as well as with the evaluation of track quality and their maintenance. It has a direct influence on the position of rail transport in the frame of the whole transport system, on economics, ecology and so on.
\end{abstract}

Keywords: geometric characteristics, wheel and rail contact point detection, wheel tread profile definition, rail head profile specification, new profile creation method

\section{Introduction}

The wheel/rail geometry is one of the main parameters dramatically influencing track forces and vehicles dynamic. The resulting wheel geometry in service conditions depends upon the new assumed profile, the track geometry distribution, the creep coefficients and forces, the rail average material and mechanics, the wheel material and mechanics, the lubrication. The rail geometry in service depends mainly upon the new assumed profile, the track geometry at location, the service load, the wheel shape, the rail material and mechanics, the lubrication. The evolution of wheel profile used to be validated in exemplar application cases, on the basis of available results or through dedicated measuring campaign.

In the article we will deal with the railway wheel/rail contact from the point of view of wheels and rails profiles geometry [1-6].

\footnotetext{
* Corresponding author: juraj.gerlici@fstroj.uniza.sk

Reviewers: Czestaw Kundera, Justín Murín
} 


\section{Railway wheel/rail contact in the frame of railway vehicles interoperability}

Problems of the railway wheel/rail contact represents a basic point of any analysis which is connected with the moment of a railway vehicle on a track, with safety, speed, with comfort of people and goods transport.

It is connected with the construction of new railway vehicles, with the reconstruction the old ones, with the approval (refusal) of vehicles into operation, with their evaluation as well as with the evaluation of track quality and their maintenance. It has a direct influence on the position of rail transport in the frame of the whole transport system, on economics, ecology and so on.

Profiles shapes (we understand a profile curve course which a rail and wheel have in a lateral cross section, or at a rail in a cross section which is perpendicular on the rail axis and at a wheel with a plane which is crossing the wheel centre point and which is perpendicular on a plane of a wheel lateral cross section) as we know them today have been developing since the beginning of railway.

The shape of wheel tread and rail head profiles has been developed together with the satisfaction of needs on the goods and people transport when looking at the enhancement of wheelset loading for heavy haul transport and speed for passenger and heavy haul transport as well.

Nowadays several basic wheels and rails profiles types are used on various European railways. It depends on a specific railway company of the given country whether one type of rails equipped with a standardised profile or several types of profiles are used in its railway corridors.

The aim of each railway company is (or should be) that the wheel/rail contact couple provides the best presuppositions for a smooth, safe (stable) and quiet vehicle running on a track with a minimum wheels and rail wearing, with a minimum negative force influence of a wheel on the track.

The fact that various types of rails with different types of profiles, with different slopes are used at separate companies complicates the situation. The track gauge complicates it to a smaller degree.

Today there is an extremely up to date need for the security of vehicles interoperability in its greatest extend in order to use in reality one of the greatest advantages of railway transport (economic transport of a huge volume of goods over long distances). The fulfilment of the need places a higher requirement on the sphere of usage (design or choice of the right, for the given railway company so called optimum profile).

It arises from the variety of inputs and transport needs of separate railway companies that it is not easy at all to find one profile which solves all the problems.

It is possible to use a proved and verified standard in a higher degree when building new modern tracks and railway corridors.

As a result of real conditions of a railway track in certain European regions at specific utilisation (the way of operation, loading, accessibility, simplicity and economic demands for the track maintenance), it has a sense to adapt for example a wheels profile to rail head profiles or for a certain track type to vehicles equipped with a certain wheels profile to find a rails profile which improves a mutual vehicle/rail interaction.

In order to declare a profile or a couple of profiles (wheel/rail) for a better one than another profiles couple, it is necessary to analyse both the existing and new state on the base of unambiguous criteria.

Such input criteria, after fulfilment of which verification in operation must of course follow, are geometrical characteristics. 
When assessing characteristics in the article we take into consideration neither the wheelset rotation around its axis which can happen at a lateral movement of a wheelset in a rail, nor the wheelset angle of attack [7-11].

\section{Wheel and rail profiles geometry analysis}

The geometric shape of theoretical wheels and rails profiles is usually defined in a table way, with radii (and centres) of to each other linked arcs, or by functional dependence of a vertical profiles points position with regard to a lateral coordinate $y$.

The role of the smoothing is to keep the profile geometry characteristics and to minimize influence of possible imperfections of measurements. Theoretical profiles are not smoothed. Profiles and arcs radii values from which the profiles are created with regard to a lateral coordinate $y$ are graphically depicted in Fig. 1a and Fig. 1b. Theoretical profiles: wheel profile DIN5573 (marked S1002) and rail UIC60 are analysed separately in the figures.

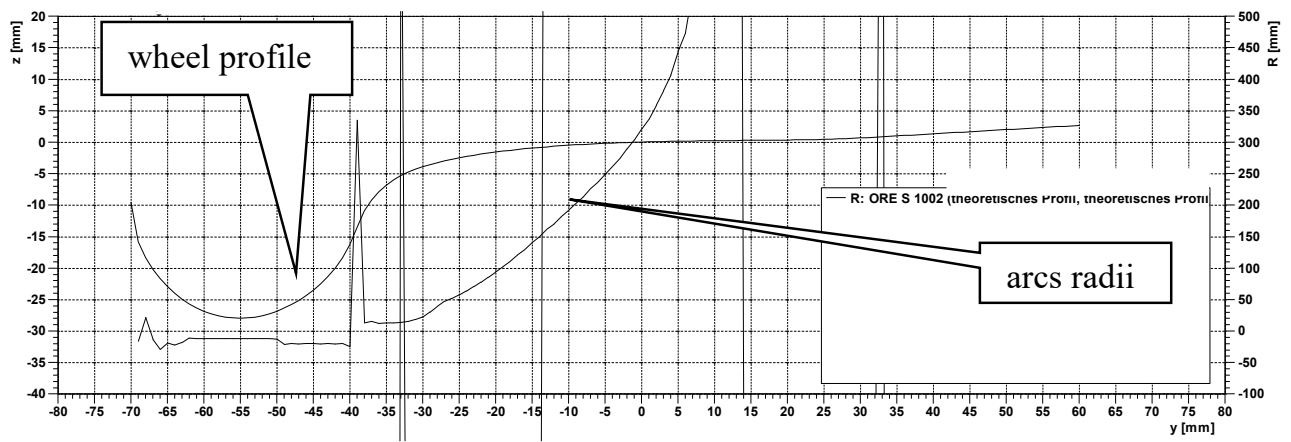

Fig. 1a. Course of theoretical wheel profile arcs radii values of S1002 with regard to a lateral profile coordinate $y$

Profiles acquired from the measurements have a base in points which are determined with couples of coordinates. It is often necessary to smooth such profiles for further assessment.

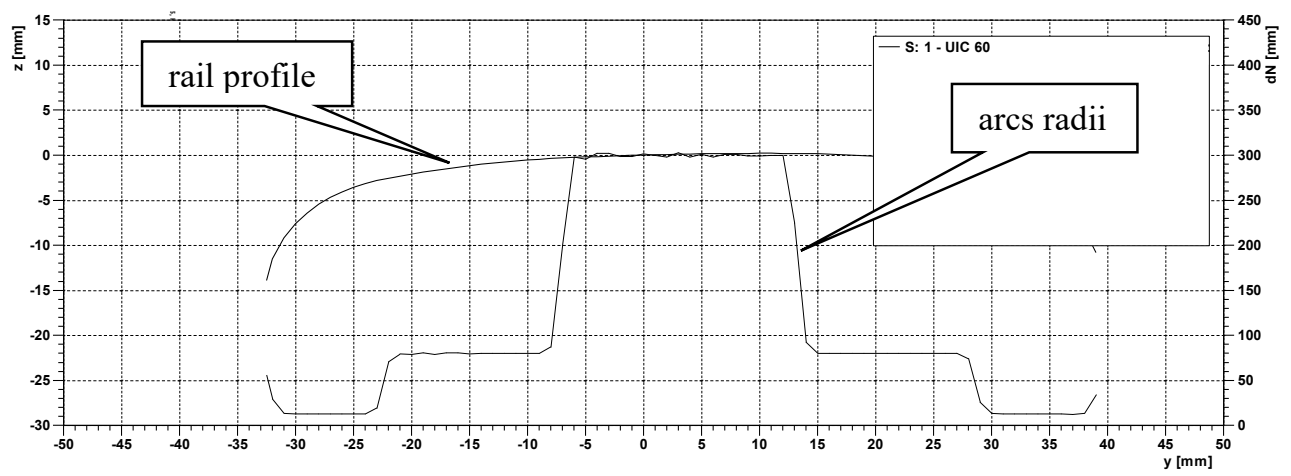

Fig. 1b. Course of theoretical rail head profile arcs radii values of UIC60 with regard to a lateral profile coordinate $y$ 


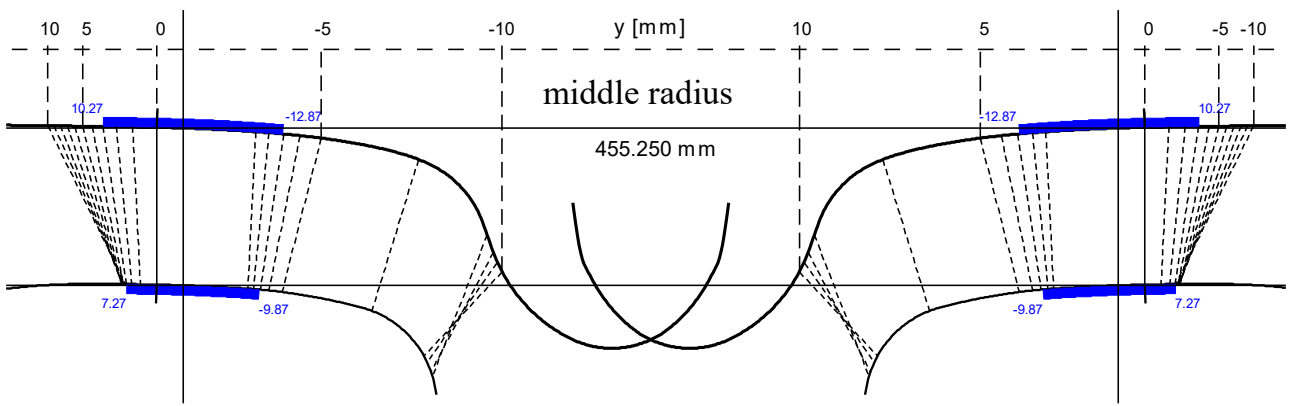

Fig. 2. Contact points at profile combination S1002/UIC60/1:40/1435 with marking of contact points position interval at a wheelset lateral movement in a rail for amplitude of $3 \mathrm{~mm}$ (Common situation)

In Fig. 3 there is a course of theoretical wheel profile arcs radii values of S1002 in the contact points with regard to wheelset lateral movement $y$.

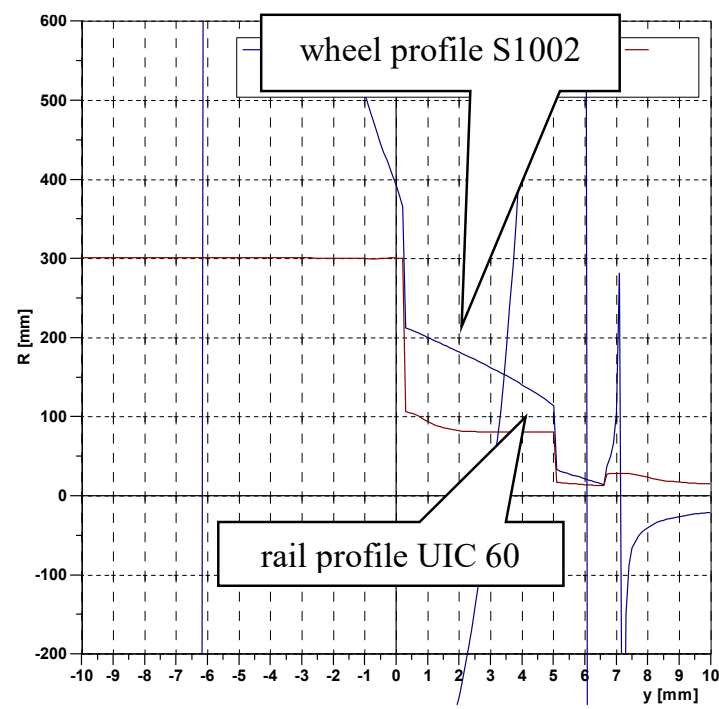

Fig. 3. Course of theoretical wheel profile arcs radii values of S1002 and rail UIC60 in the contact points with regard to wheelset lateral movement $y$

\section{Wheelset and rail geometric characteristics}

Wheelset and rail geometric characteristics help to specify the geometric binding of a wheelset and rail. With the help of them, it is possible relatively quickly to assess some parameters of the binding which help to estimate as a vehicle or better to say a wheelset can behave in a real operation.

We understand under the name of geometric characteristics the following: contact points distribution between a wheel and rail at a lateral movement of wheels profiles of a wheelset over rail heads profiles, delta $\mathrm{r}$ function, tangent gamma function and equivalent conicity function. The basic presupposition for the characteristics evaluation is detailed knowledge of a wheel and rail profiles geometric shape. 
To make the information complete, it is necessary to mention separate geometric characteristics. On the base of their shape we will suggest a railway wheel profile shape (to the given rail profile) or a rail head profile shape (to the supposed railway wheel shape).

They are as follows:

- contact points between wheel and rail determine the contact points position at a wheel profile lateral movement over the rail profile. If we can presuppose, that left and right wheel profiles (as well as rail profiles) are identical, the final curve course is symmetrical with regard to the rail axis,

- delta $r$ function is a difference between an instant diameter of running of one wheel of a wheelset and instant diameter of running (course) of other wheel of a wheelset at the lateral movement of a wheelset on a rail. The delta $r$ function course shape indicates the rotating tendency of a wheelset at its lateral movement in a rail or kinematics running ability of a wheelset through the track arc,

- tangent gamma function is a difference between the value of the normal line tangent angle of the tangential contact area in the contact point and vertical axes of a rail. It determinates the rate of binding intensity which comes back the wheelset after its lateral deviation into a centred equilibrium position on the rail. The tangent gamma function has (like the delta $r$ function) anti-symmetrical course for the same wheels and rails profiles and it crosses the horizontal coordinate axis in its zero point.

Equivalent conicity is a reference conicity which equals the curving profile of a wheel when taking into consideration the amplitude of a coned wheel movement. According to the definition of UIC519 it is such conicity of a simple cone wheelset profile which the wheelset should possess in order to have the same kinematics characteristics as a wheelset with a curved profile at a certain oscillation amplitude.

\section{New optimum profiles statement}

It is not possible to state a generally optimum profile for all types of tracks and railway wheels. The main reason is that in operation there are tracks with various gauges, various rail heads profiles on which vehicles with various railway wheels profiles move. Vehicles move at various speed, with various wheel forces, they transport various goods and more over we require various kinematics behavior. That is why it is very difficult to state unambiguous criteria which we could define and compare when taking into account all vehicles.

We have chosen geometric characteristics of a railway wheelset and rail, we will state our optimum real or rail profile on the base of their specific shape.

\subsection{Criteria for the search of an optimum profile}

We have stated the following conditions as criteria for optimizing process:

- delta $r$ function shape without jump change of the course,

- requested equivalent conicity,

- fluent distribution of contact points on the wheel and rail surface,

- exclusion of two-point contact.

The difference function course shape (delta $r$ ) without jumps indicates continual increase in lateral forces in the wheel and rail contact point without kick bounces and additional dynamic exciting of the vehicle mechanical system. This phenomenon is shown on the value of safety against derailment.

The size of instant equivalent conicity value is connected with the size of wavelength of periodic oscillation movement which a wheelset performs. A low conicity value presupposes a higher wavelength value. Sufficient wavelength size is extremely important for a high speed 
railway operation. The size of equivalent conicity is projected into the stability of vehicle movement and riding comfort of passengers.

The determining value of equivalent conicity is stated at the movement amplitude of $3 \mathrm{~mm}$. Contact points distribution across the profile has a crucial influence on wearing (resistance against wearing) of wheel and material and at the same time the geometric stability of their profiles.

From the nature of the way of geometrical characteristic evaluation it is clear that it is not possible to suggest profile geometry directly on the base of contact points position setting. Various authors have applied various procedures where continual profile shape modification on the base of a geometric characteristic was the starting point [7-11].

\subsection{Profiles creation method through arcs radii profile variation}

We have used the method of arcs radii profiles variation for the creation of new profiles which are suitable for the given criteria.

The base of the activity is an interactive attitude which is based on the modification of the original shape defined by parts of railway wheel profile with to each other linked exactly defined arcs radii which it is possible to change according to the need to the final geometric characteristics shape.

\subsubsection{Arcs radii profile variation}

The basic procedure is as follows:

- we have the profile of the rail of UIC 60 1:40,

- we have a requested shape of geometric characteristics: it is low equivalent conicity $\leq$ of 0.05 in the given case,

- we choose a "suitable" wheel profile: we will choose the up to now used profile of S1002.

- we perform numerical division of the whole existing wheel profile in order to obtain simple geometric parts,

- we create the radii function $R(y)$ (in dependence on the lateral wheel profile coordinate).

- we set the starting conditions in the equation (10): in the given example, it is the first derivation $=$ tangent value in the starting point $=0.05$,

- we change the selected radius (from the original S1002 profile radii) and compute the equation (3),

- when the new profile is derived, the geometric characteristics are evaluated and the results are assessed. If the results meet our expectations, the profile is accepted, if the results do not fulfill our expectations, the selected radius (radii) is (are) changed and computations have to continue. In this case, there is a need for knowledge and for experience and skills in the radius selection and radius value for the determination of the change.

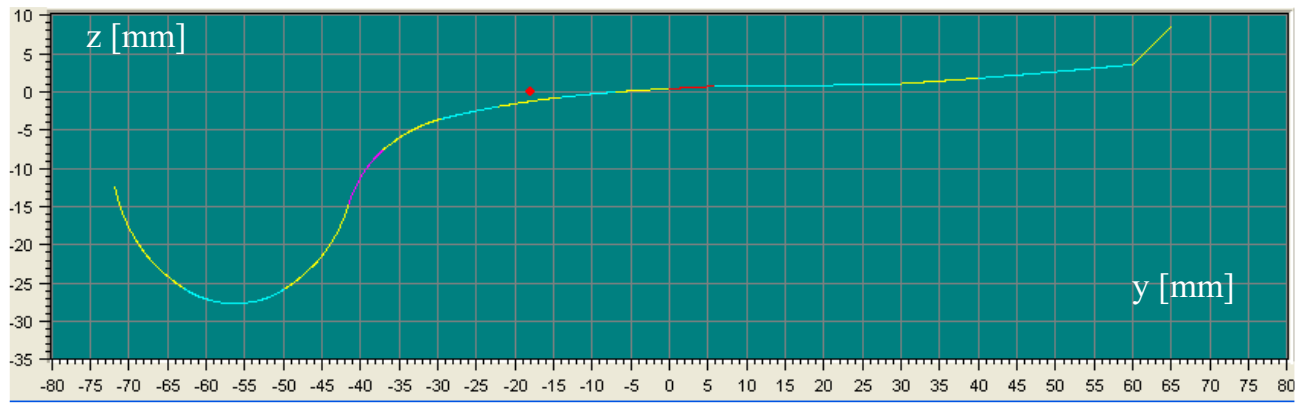

Fig. 4. Wheel geometry profile radii setting 


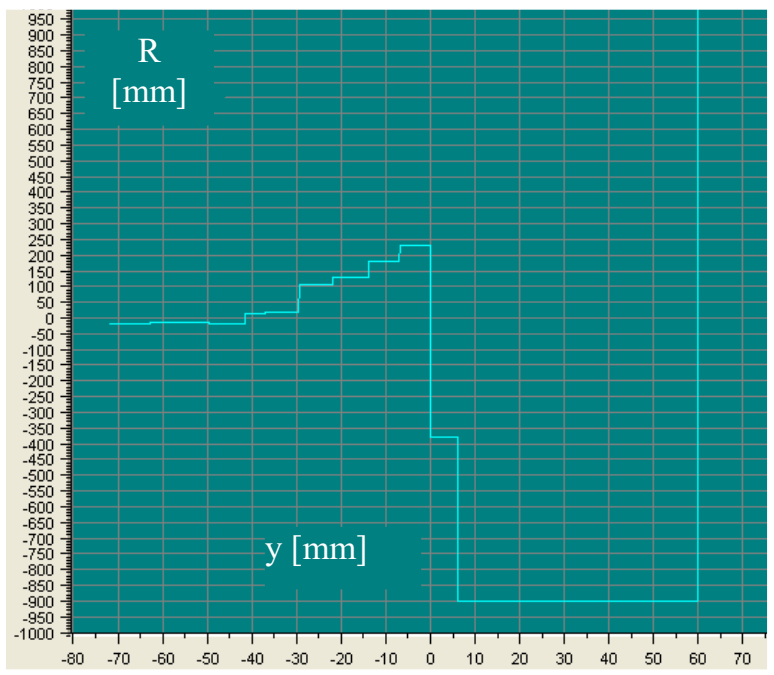

Fig. 5. Arcs radii values course of the suggested wheel profile

\subsubsection{Profile creation on the base of the given functional dependence of radii depending on the coordinate $y$}

Nyström method which is described in the relationship from 4 to 7 has been used for the solution of the differential function (3) arising from the relationship for curvature. Its application for the solution of the function (3) is in relationship (8) and (9). The starting conditions are defined in the equation (10).

The radii function $R$ depends on the lateral movement $y, z$ is a vertical profile coordinate.

$$
\begin{gathered}
R=R(y) \\
\frac{1}{R(y)}=\frac{z^{\prime \prime}}{\left[1+\left(z^{\prime}\right)^{2}\right]^{\frac{3}{2}}} \\
z^{\prime \prime}=\frac{\left[1+\left(z^{\prime}\right)^{2}\right]^{\frac{3}{2}}}{R(y)}
\end{gathered}
$$

Basic relationships for the solutions of a differential function by Nyström method.

$$
\begin{aligned}
& k_{1}=f\left(y_{m}, z_{m}, z_{m}^{\prime}\right) \\
& k_{2}=f\left(y_{m}+\frac{h}{2}, z_{m}+\frac{h}{2} \cdot\left(z_{m}^{\prime}+\frac{h}{4} \cdot k_{1}\right), z_{m}^{\prime}+\frac{h}{2} \cdot k_{1}\right) \\
& k_{3}=f\left(y_{m}+\frac{h}{2}, z_{m}+\frac{h}{2} \cdot\left(z_{m}^{\prime}+\frac{h}{4} \cdot k_{1}\right), z_{m}^{\prime}+\frac{h}{2} \cdot k_{2}\right) \\
& k_{4}=f\left(y_{m}+h, z_{m}+h \cdot\left(z_{m}^{\prime}+\frac{h}{2} \cdot k_{3}\right), z_{m}^{\prime}+h \cdot k_{3}\right) \\
& k=\frac{1}{6} \cdot\left(k_{1}+k_{2}+k_{3}\right) \\
& k^{\prime}=\frac{1}{6} \cdot\left(k_{1}+2 \cdot k_{2}+2 \cdot k_{3}+k_{4}\right)
\end{aligned}
$$


$k_{n}$ are auxiliary variables for determination a profiles points vertical coordinate, $h$ is computational step, we have used $h=0.005 \mathrm{~mm}$ :

$$
\begin{aligned}
& y_{m+1}=y_{m}+h \\
& z_{m+1}=z_{m}+h \cdot\left(z_{m}^{\prime}+h \cdot k\right) \\
& z_{m+1}^{\prime}=z_{m}^{\prime}+h \cdot k^{\prime}
\end{aligned}
$$

Application of Nyström method for the solution of the equation (3)

$$
\begin{aligned}
& k_{1}=\frac{\left[1+\left(z_{m}^{\prime}\right)^{2}\right]^{\frac{3}{2}}}{R\left(y_{m}\right)} \\
& k_{2}=\frac{\left[1+\left(z_{m}^{\prime}+\frac{h}{2} \cdot k_{1}\right)^{2}\right]^{\frac{3}{2}}}{R \cdot\left(y_{m}+\frac{h}{2}\right)} \\
& k_{3}=\frac{\left[1+\left(z_{m}^{\prime}+\frac{h}{2} \cdot k_{2}\right)^{2}\right]^{\frac{3}{2}}}{R \cdot\left(y_{m}+\frac{h}{2}\right)^{2}} \\
& k_{4}=\frac{\left[1+\left(z_{m}^{\prime}+h \cdot k_{3}\right)^{2}\right]^{\frac{3}{2}}}{R\left(y_{m}+h\right)}
\end{aligned}
$$

Initial conditions:

$$
\begin{aligned}
& z\left(y_{0}\right)=z_{0} \\
& z^{\prime}\left(y_{0}\right)=z_{0}^{\prime}
\end{aligned}
$$

have been specified in this way:

$$
\begin{aligned}
& y_{0}=0 \\
& z_{0}=0 \\
& z_{0}^{\prime}=t g \text { profile tangent slope. }
\end{aligned}
$$

Initial condition secure that the beginning of the profile coordinate system is placed in horizontal direction into the plane of nominal wheel radii circle and the profile crosses the beginning.

First $z_{0}^{\prime}$ coordinate derivation determines the tangent value of the profile tangent slope in the point $\left[y_{0}, z_{0}\right]$. The profile is created by the solution of the differential function (3) continually from the point $\left[y_{0}, z_{0}\right]$ to the left side and then from the point $\left[y_{0}, z_{0}\right]$ to the right side.

\subsubsection{Results of application of the chosen method}

Wheel profiles (NEWRAD) which correspond to our needs thanks to their properties have been created on the base of the chosen input parameters at defined optimizing criteria. 


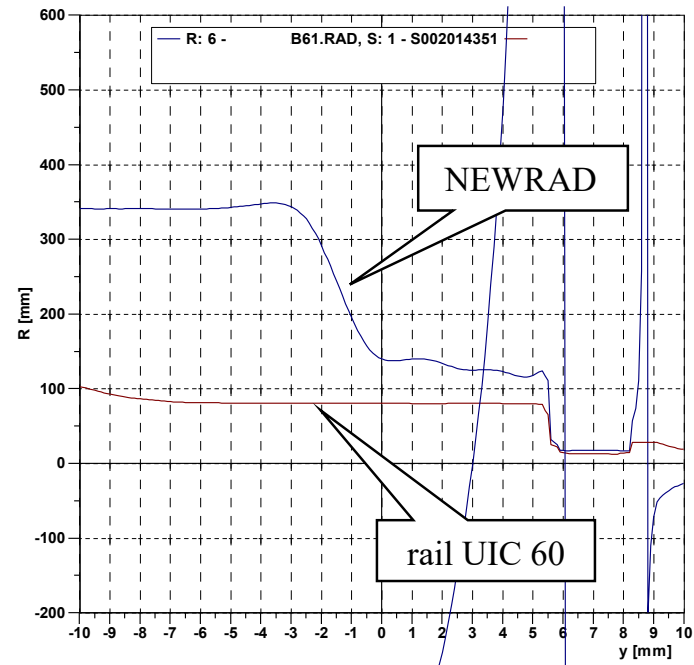

Fig. 6. Profiles radii NEWRAD and UIC60 at contact points

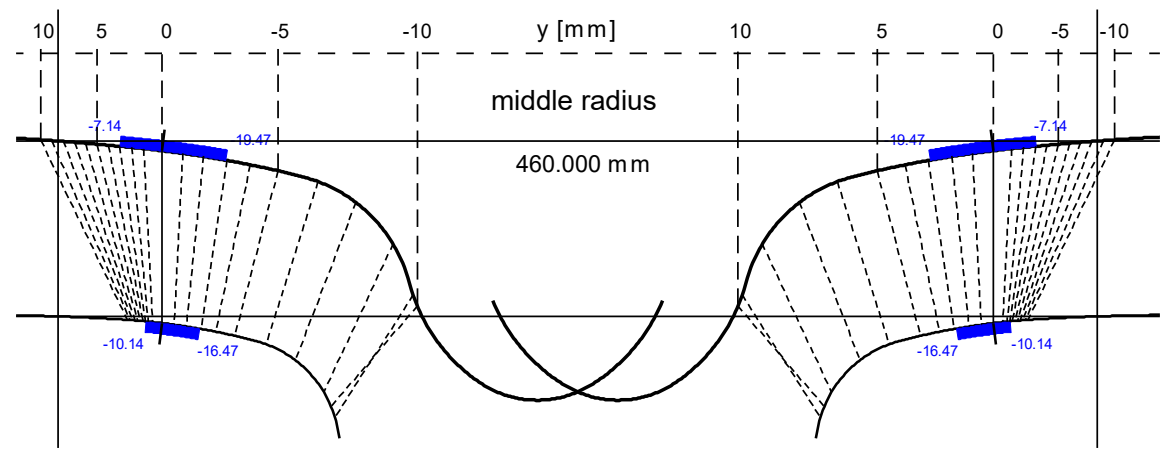

Fig. 7. Contact points at profiles combination NEWRAD/UIC60/1:40/1435 with marking of contact points interval at a wheelset lateral movement in a rail with amplitude of $3 \mathrm{~mm}$

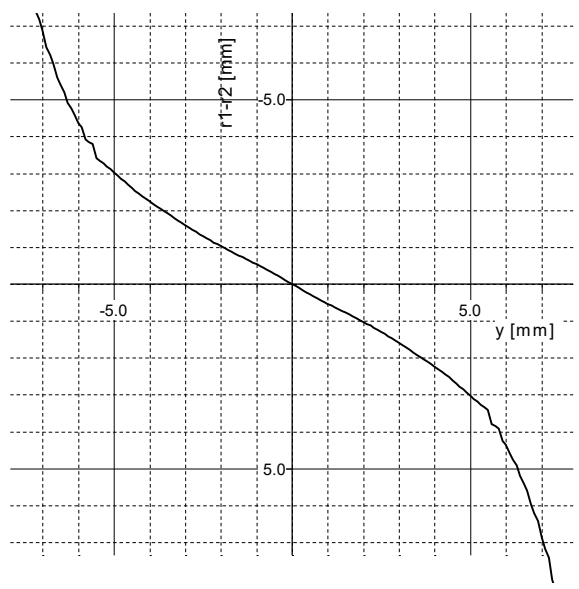

Fig. 8. Delta $r$ function for the profiles combination NEWRAD/UIC60/1:40/1435

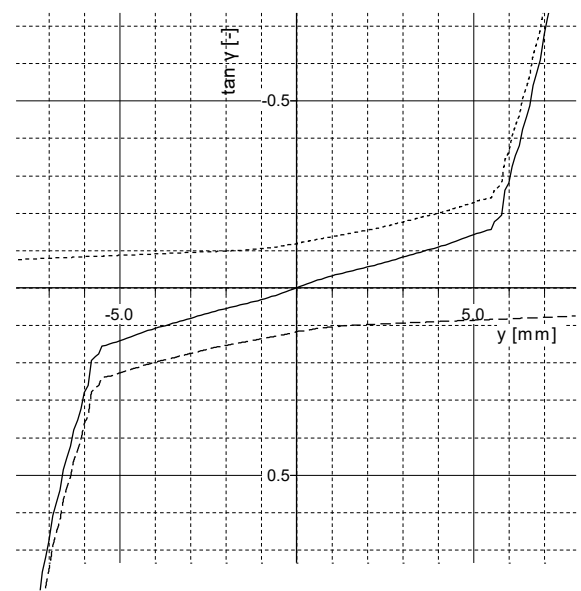

Fig. 9. Tangent gamma function for the profiles combination NEWRAD/UIC60/1:40/1435 


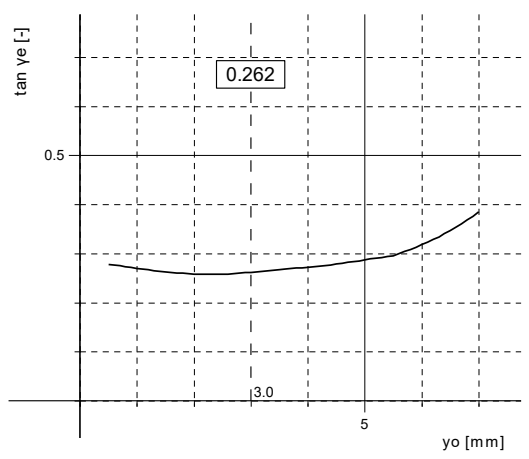

Fig. 10. Equivalent conicity function for the profiles couples NEWRAD/UIC60/1:40/920/1435

\subsection{Arcs radii profile variation for the creation of an outer rail profile for a track in a left arc}

It is possible to create a rail profile (NEWRAIL) in the similar way like the wheel profile (NEWRAD) has been created. Let us suppose that it is necessary to create an outer rail profile for a track in a left arc in order to fulfil basic criteria.

We require the following criteria for the new profile: fluent distribution of contact points at a wheelset lateral movement in a rail, no jump course changes of the difference delta $r$ function, low equivalent conicity, the best possible wheelset kinematics movement ability even in the case of small arcs at a small lateral movement, exclusion of two-point-contact. The principal of the activity is similar to the one at the wheel profile, it is an interactive attitude based on the modification of the "original shape" which is defined by rail profile parts with to each other linked exactly defined arcs radii. It is possible to change the radii size according to need of final geometric characteristics shape. The basic profile is divided into parts with precisely defined geometry (radius). The radii function $R$ which is dependent on $y$ (see part 3) is created. We will modify the function. The differential equation (3) is solved. We set initial conditions which place the profile into the beginning of the coordinate system and they tilt it in this point according to our needs. We calculate the points position of the new profile. We calculate the geometric characteristics. If the shape of the characteristics is not suitable we modify the radii function and repeat the procedure.

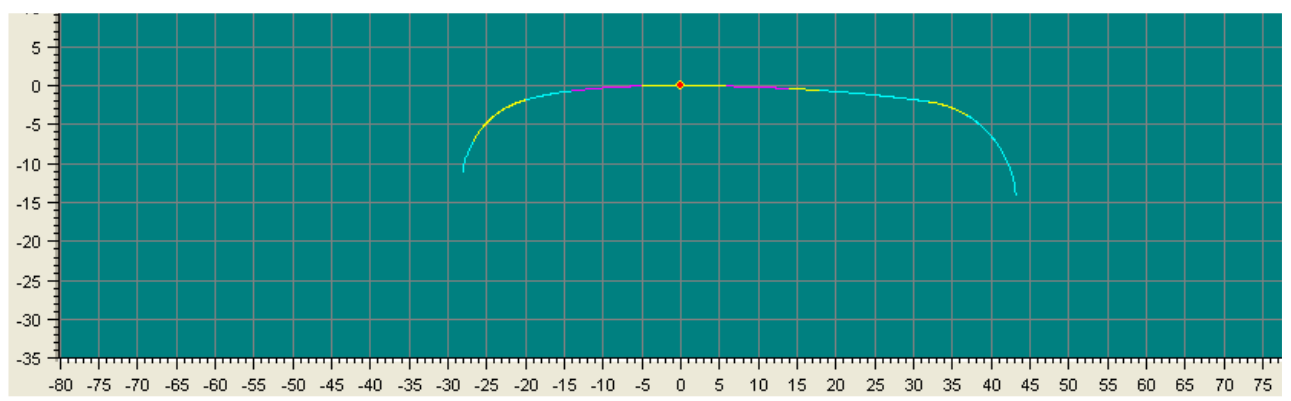

Fig. 11. Geometry radii display of separate rail profile parts 


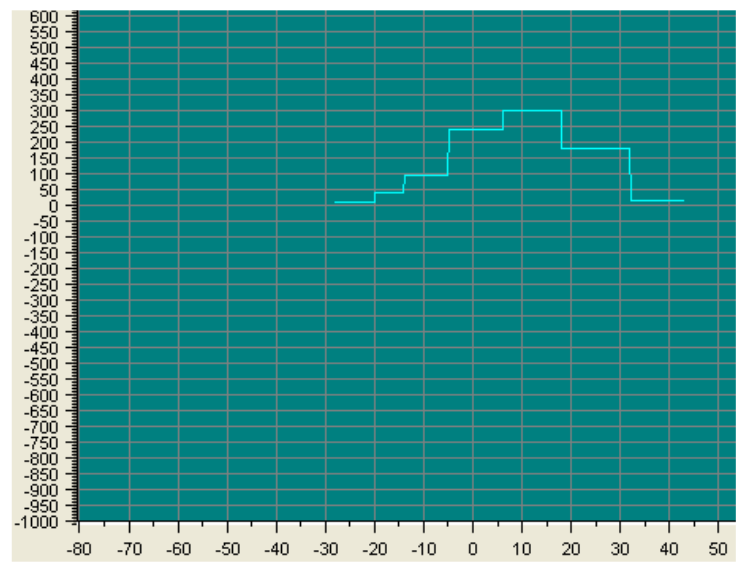

Fig. 12. Depiction of rail head profile arcs at contact points
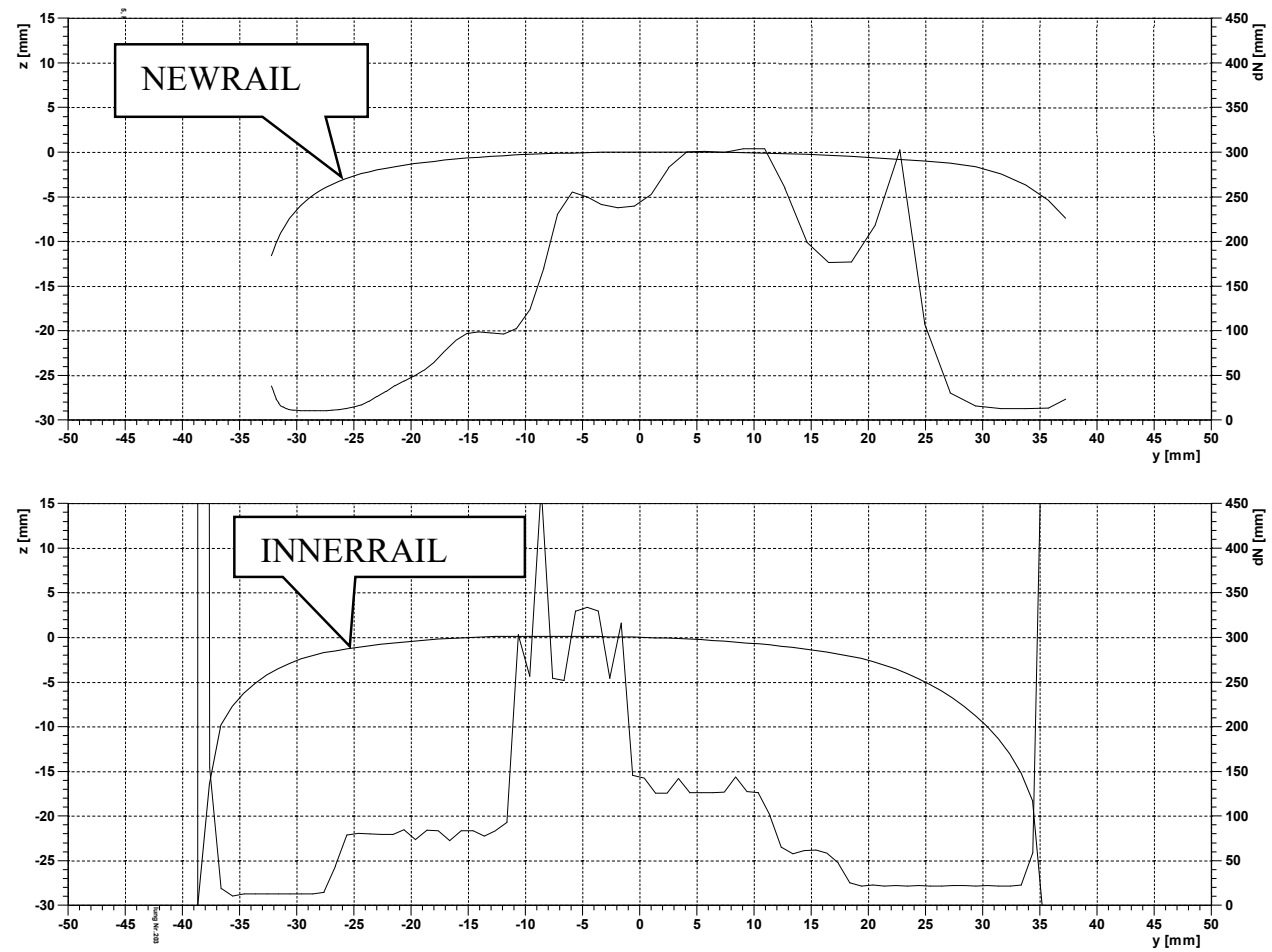

Fig. 13. Profiles and profiles radii NEWRAIL and INNERRAIL

INNERRAIL is an inner rail, NEWRAIL is an outer rail of the track. We suggest and analyse the profile for the outer rail. 


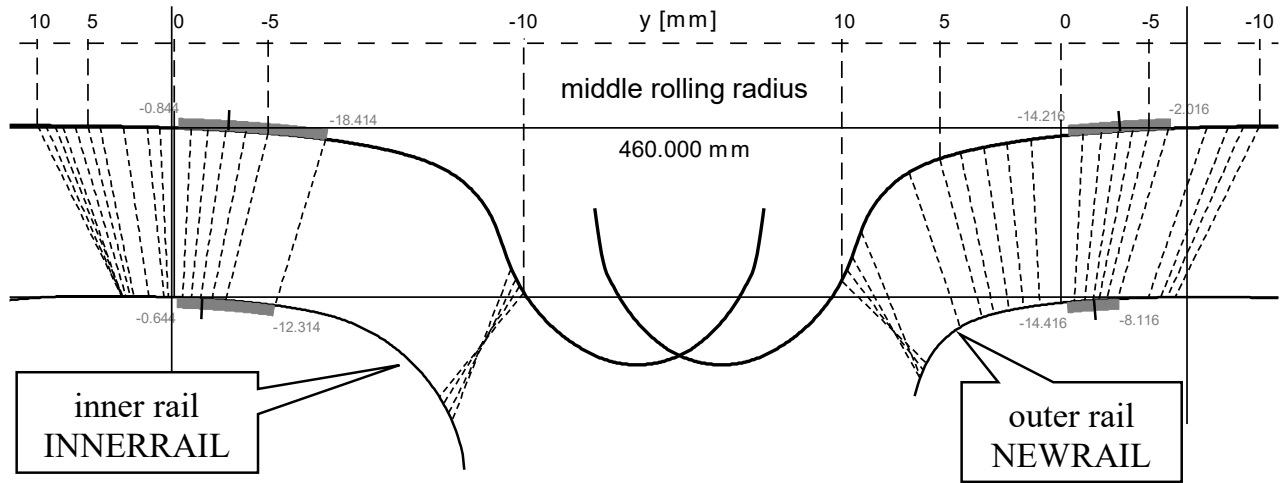

Fig. 14. Depiction of wheelset contact points with profiles S1002 and rails profiles INNERRAIL and NEWRAIL

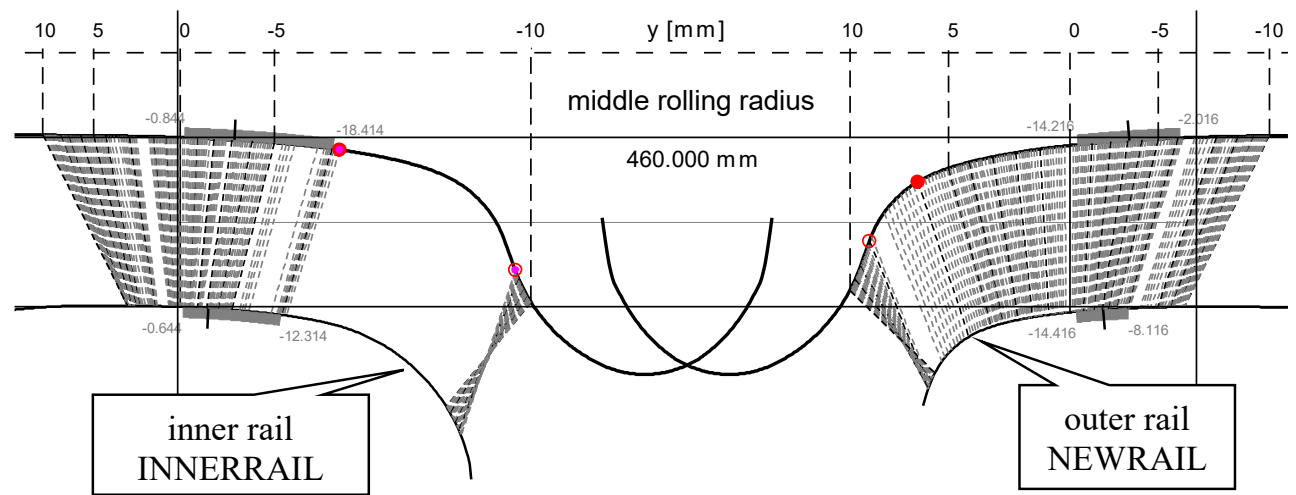

Fig. 15. Detailed view of wheelset contact points distribution with profiles $\mathrm{S} 1002$ and rail profiles

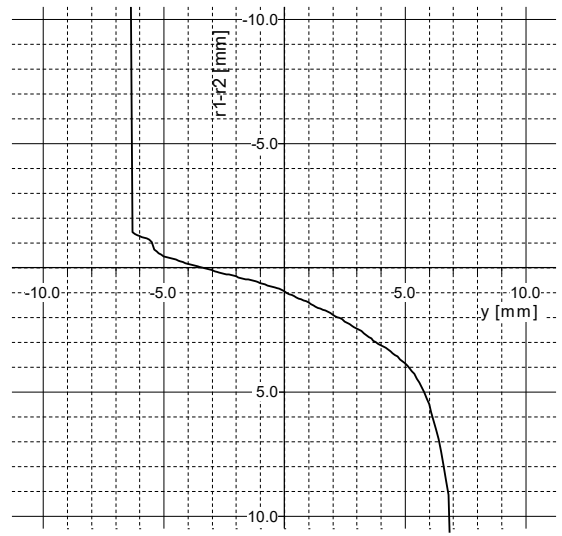

Fig. 16. Delta $r$ function for the given profiles configuration

It is clear from Fig. 17 that a wheel equipped by the S1002 profile can move in a kinematic way through the rail arc radii with an outer rail profile NEWRAIL with the value of approximately of $600 \mathrm{~m}$. This happens at the given configuration already at zero lateral displacement. It can move in a kinematic way through a radius smaller than $150 \mathrm{~m}$ at lateral displacement of $5 \mathrm{~mm}$. It is not possible when combining the wheel profile $\mathrm{S} 1002$ and the profile UIC60 (Fig. 18). 


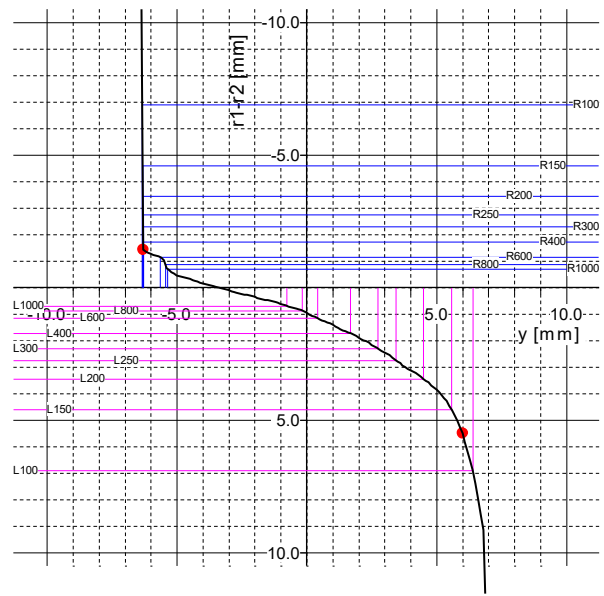

Fig. 17. Delta $r$ function with marked radii for a kinematic movement through a track arc for the rail profile NEWRAIL and wheel profile S1002

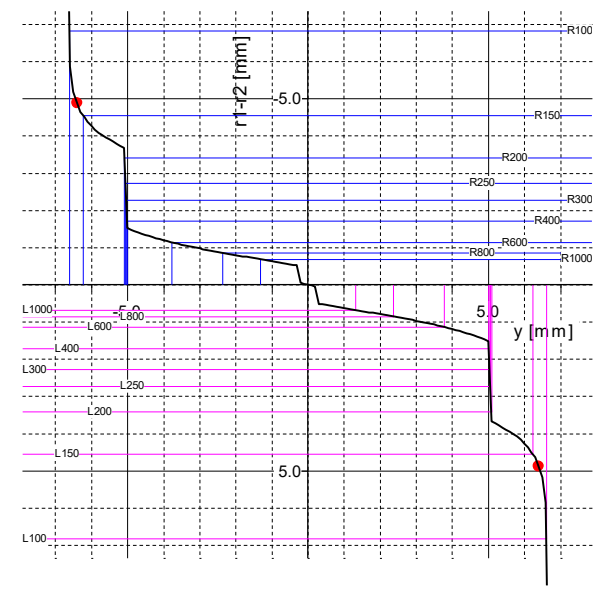

Fig. 18. Delta $r$ function with marked radii for a kinematics movement through a track arc for the rail profile UIC60 and wheel profile S1002

The tangent gamma function in Fig. 19, similarly like the delta $r$ function, has the horizontal axis cross section point shifted against the beginning of the coordinate system.

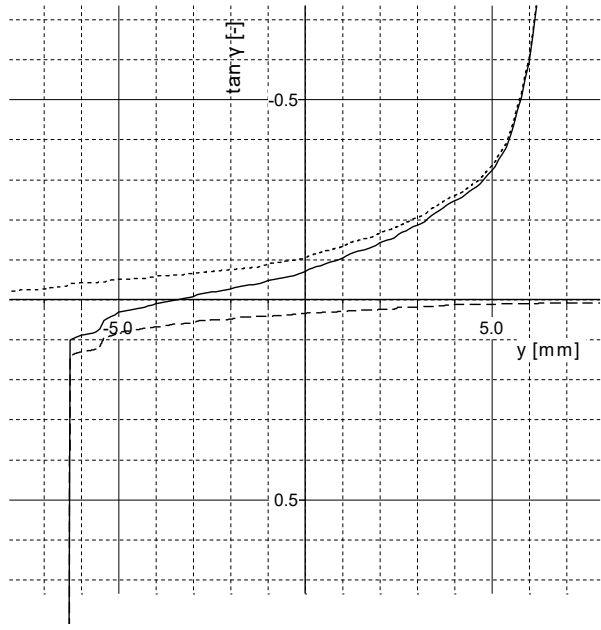

Fig. 19. Tangent gamma function for the given profiles configuration

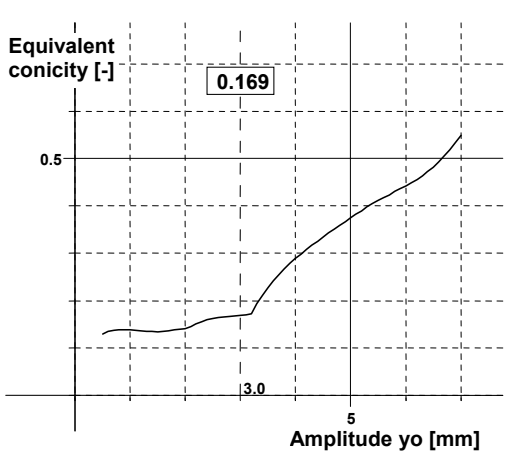

Fig. 20. Equivalent conicity

\section{Conclusions}

The article deals with one of the ways of profile geometry design of a railway wheel and rail, or rail head profile on the base of the chosen criteria. On the base of the geometric characteristic shape definition we have suggested a railway wheel profile shape (to the given rail profile) NEWRAD and a rail head profile shape (to the supposed railway wheel shape) NEWRAIL.

So from the above mentioned arises that the wheel profiles NEWRAD with characteristics according to Fig. 7-10 and the rail head profiles NEWRAIL with characteristics according to 
Fig. 14-20 (excluding Fig. 18) are the solution for the following criteria: fluent distribution of contact points at a wheelset lateral movement in a rail, no jump course changes of the difference delta $r$ function, low equivalent conicity, the best possible wheelset kinematics movement ability even in the case of small arcs at a small lateral movement, exclusion of two-point contact.

The profiles on the base of the assessed characteristics represent an approach to an optimum solution for certain presupposed operational conditions and required manner of vehicle running.

A profile with different geometry will be a result in a case of change of initial parameters which can be represented for example by a change of geometry of one from contact couple profiles or a change of vehicle operation manner (a need for different equivalent conicity). With this research and development subjects deals other publications too [12-25].

The work was supported by the Cultural and Educational Grant Agency of the Ministry of Education of the Slovak Republic in project No. KEGA 077ŽU-4/2017: Modernization of the Vehicles and engines study program. The work was also supported by the project No. APVV-0842-11: Equivalent railway operation load simulator on the roller rig and VEGA No. 1/0558/18: Research of the interaction of a braked railway wheelset and track in simulated operational conditions of a vehicle running in a track on the test stand.

Research-Educational Center of Rail Vehicles (VVCKV)

\section{References}

1. J. Gerlici, T. Lack, Railway wheel and rail geometry influence on ride properties of the vehicle (in Slovak). 16. International Conference PRORAIL 2003 - Current problems in rail vehicles, Universtity of Žilina, 163-171 (2003), ISBN 80-968823-6-8

2. J. Gerlici, T. Lack, Contact of a railway wheelset and a rail (in Slovak). Scientific monograph, EDIS - publishing house of University of Žilina, (2004), ISBN 80-8070$317-5$

3. J. Gerlici, T. Lack: Transport Means properties Analysis - Vol. I. Monography, ,. EDIS - Publishing house of University of Žilina, 214 (2005), ISBN 80-8070-408-2

4. J. Gerlici, T. Lack, M. Kadorová, Calculation of the equivalent conicity function of the railway wheelset tread profile at the Delta $R$ function with a negative slope. Communications - Scientific Letters of the University of Žilina, 6, 2, 49-56 (2004), ISSN $1335-4205$

5. T. Lack, J. Gerlici, Contact area and normal stress determination on railway wheel / rail contact. Communications - Scientific Letters of the University of Žilina, EDIS Publishing house of University of Žilina, 38-45 (2005), ISSN 1335-4205.

6. T. Lack, J. Gerlici, Profiles synthesis through radii variation of arcs profile. (In Slovak). Current problems in Rail Vehicles, DFJP UP, DP Česká Třebová, 115-135 (2005), ISBN 80-7194-780-6

7. H. Lehna, A. Theiler, Radprofiloptimierung bei der Verkehrsbetrieben Zürich. Rad Schiene. 6. Internationale Schienenfahrzeugtagung, Dresden, 42-50 (2003).

8. R. Müller, Die Problematik der Berührungsgeometrie Rad/Schiene. ZEV+DET Glas. Ann. 118, 3 März, Georg Siemens Verlagsbuchhandlung (1995).

9. R. Müller, Zusammenwirken von Rad- und Schienenprofilen. Rad Schiene 2003, 6. Internationale Schienenfahrzeug-tagung, Dresden, 30-34 (2003).

10. A. Neftzger, Geometrie der Berührung zwischen Radsatz und Gleis. ETR Eisenbahntechnische Rundschau, 3, 113-122 (1974), DK 681.938:625.1/.2.031.3 
11. E. Scheunemann, T. Kolbe, R. Müller, Geometrie Rad/Schiene, ein gemensames Thema für Fahrzeug und Fahrweg. ZEV+DET Glas. ZEVrail Glasers Annalen 129, Tagungsband SFT Graz 2005. Georg Siemens Verlagsbuchhandlung, 168-189 (2005).

12. B. Bergander, G. Dendl, A. Neftzger, D. Nicklisch, Die Entwicklung von Rad- und Schienenprofilen. ZEVrail Glasers Annalen 127, $482-503$ (2003)

13. P. Baran, M. Brezáni, P. Kukuča, P. Št’astniak, Basic dynamical analysis and comparison of balancing systems of non-conventional piston machine FIK. Procedia Engineering, 192, 34-39 (2017), ISSN 1877-7058

14. C. Bußmann, A. Neftzger, Die Entwicklung von Schienenprofilen unter dem Einfluß von Verschleiß und die Auswirkungen auf das quasistatische Kurvenlaufverhalten eines Fahrzeuges. VDI Berichte NR.820, Systemdynamik der Eisenbahn (1990).

15. T. Hayashi, M. Toyama, K. Hino, M. Isa, Development of wheel tread nicknamed "CS Tread" for narrow gauge lines. World congress on railway research Tokyo, Japan, 195198 (1999).

16. J. Izer, Efective and equivalent conicity of the wheel tread profil of railway wheelset. (In Czech) PRORAIL'95 Current problems in rail vehicles, VŠDS Žilina (1995).

17. EN 13715:1999, Bahnanwendungen, Radsätze und Drehgestelle, Räder - Radprofile. Deutsche Fassung EN 13715:1999.

18. Z. Riečanová, at al., Numerical methods and mathematical statistics. (In Slovak). University textbook, Alfa Bratislava (1987), 063-559-87 NMA

19. K. Sasaki, K. Kageyama, K. Asano, M. Okumura, Development of the wheel tread profile for commuter train (Investigation of the wear profile of the wheel tread and the rail head. Proc. the 5-th International Conference on Contact Mechanics and Wear of Rail/Wheel Systems CM2000 (SEIKEN Symposium 27), Tokyo, 265-270 (2000).

20. M. Sága, M. Letrich, R. Kocúr, An Analysis of Vehicle Vibration with uncertain system parameters. Communications - Scientific letters of the University of Žilina, EDIS Publishing house of University of Žilina, 16-21 (2005), ISSN 1335-4205

21. G. Shen, J. Ayasse, H. Chollet, I. Pratt, A unique design method for wheel profiles by considering the contact angle function. Proc. Instn. Mech. Engrs, 217 Part F.: J. Rail and Rapid Transit, IMechE, 25-30 (2003), F01902

22. P. Baran, P. Št’astniak, P. Kukuča, M. Brezáni, Investigation of kinematic parameters of two nonconventional piston machines with wobble board. MATEC Web of conferences 157 (2018), ISSN 2261-236X

23. L. Smetanka, P. Št’astniak, J. Harušinec, Wear research of railway wheelset profile by using computer simulation. MATEC Web of conferences 157 (2018), ISSN 2261-236X

24. P. Št’astniak, M. Moravčík, P. Baran, L. Smetanka, Computer aided structural analysis of newly developed railway bogie frame. MATEC Web of conferences 157 (2018), ISSN 2261-236X

25. UIC Code 519: Method for determining the equivalent conicity. Draft of January 2003 Original version (2003). 